\title{
FREIGHT FLEET MANAGEMENT PROBLEM: EVALUATION OF A TRUCK UTILIZATION RATE BASED ON AGENT MODELING
}

Ganna Samchuk, Denis Kopytkov, Alexander Rossolov*

O. M. Beketov National University of Urban Economy in Kharkiv, Kharkiv, Ukraine

*E-mail of corresponding author: rossolovalex@gmail.com

\section{Resume}

The article deals with the problem of estimating the rational number and utilization rate of the vehicles' fleet. According to the analysis results of the state-of-the-art literature it has been revealed that the issue of substantiating the rational fleet size and the rate of its utilization were not fully solved. The purpose of the study was to increase the efficiency of servicing transportation orders by determining the required number of vehicles. The goal of the research was the influence of the transportation process parameters on the truck utilization rate. Originating from the probabilistic nature of the transportation process, it has been proposed to use the AnyLogic software product to develop a simulation model for vehicle orders' servicing. From the processing of the experimental results by the regression analysis methods, it has been found that the dependence of changes in the vehicle utilization rate is of a linear form.

Available online: https://doi.org/10.26552/com.C.2022.2.D46-D58

\section{Article info}

Received 10 July 2021

Accepted 11 October 2021

Online 15 December 2021

\section{Keywords:}

freight fleet management

utilization rate

experiment

simulation

regression analysis

\section{Introduction}

The main goal of majority of the transport companies is to provide quality services to customers with minimal costs. At the same time, important factors are the number of vehicles and their utilization rate in the freight orders' service.

This is because the insufficient vehicle fleet size leads to costs associated with the inability to satisfy the order. However, large investments in the purchase, maintenance and operation of vehicles result in unreasonably high costs if the vehicle fleet utilization rate is insufficient when transporting the freight.

Thus, determination of the number of necessary vehicles and the utilization rate are the urgent tasks and, when properly solved, on the one hand, reflect in the full and timely service of transportation orders and on the other hand, contribute to an increase in the transport company's competitiveness in the field of logistics under the market economy conditions.

The purpose of this study was to increase the efficiency of servicing transportation orders by determining the required number of vehicles. The object of research is a transportation order servicing process. The goal of the research was an analysis of the influence of the transportation process parameters on the truck utilization rate.

The research objectives were to analyze the theoretical approaches; to develop a mathematical model of the order service process; to develop a simulation model of the order service process in the AnyLogic environment; to conduct experimental research; to analyze the results and give practical recommendations.

\section{Reference review}

Various types of modeling have been widely used in logistics and various transportation modes due to the obvious advantages: efficiency and saving of researchers' resources; modeling of hypothetical transportation objects and systems; implementation of processes that are difficult to reproduce in reality; possibility for the time scale change; hardware and software universality; availability of software packages for a wide operational range; possibility for the forecasting and identifying the general laws to develop a transportation and logistics process.

Thus, the research [1] deals with optimization of the warehouse operation using mathematical and statistical modeling. This made it possible to determine the warehouse operation optimal parameters and obtain a positive optimization effect expressed in a reduction of the total costs by $17.2 \%$, increase of the output flowrate by $34.6 \%$ and average input flow intensity values of $10.3 \%$.

In paper [2] authors conducted statistical modeling to optimize the waste delivery time by motor transport 
and driver's work-and-rest regimes for a European route that resulted in average delivery time reduction by 1 day.

More complex research using the fuzzy logic as a modeling tool in revealing passengers' preferences was proposed by authors in [3]. As a result, reliable statistical models were obtained to describe the opinion of various categories of passengers (adults, students and retirees) in relation to a trip fare and comfort. The modeling results can be used, particularly in forecasting a trip choice and, generally, in predicting an urban transportation development option.

So, as it can be seen from the above examples, the use of relatively simple modeling tools leads to a significant effect on transportation and logistics.

The issue of determining the optimal fleet size is relevant for both passenger and freight transportation of various modes. The proper number of vehicles leads to ensuring the completion of transportation orders and avoiding the high fixed costs associated with the vehicles that are not used at the needed rate. Several vehicle fleet management models have been proposed to consider the deterministic or stochastic input data. Deterministic models assume that the input parameters (for example, transportation demand or supply and duration of operations) are the constant values, while stochastic models take into account the probabilistic nature of processes by revealing the distribution laws of random variables.

Authors of [4] considered the fleet management problem as a dynamic one from the viewpoint of vehicle route optimization and real-time scheduling with the costs as a measure of efficiency. Study [5] presented the mixed fleet size and vehicle routing problem in maritime and road-based transportation with the issue description and categorization. Authors of paper [6] proposed the addressed or task-dependent fleet optimization to reduce operational costs. Researchers [7] limited the vehicle fleet problem to the investment volume the transport operator is ready to provide. In [8], the fleet size was believed as a trade-off between the capital and operating costs on the one hand and customer service - on the other hand. In work [9] authors believe the use of the present-day positioning and telematics systems is sufficient to quickly manage the car fleet composition on the routes. Study [10] considered the influence on the vehicle fleet composition of the transportation orders' random characteristics and in a car choice, the efficiency criterion was the specific profit. In [11], the author comprehensively studied the "fleet size (FS) and fleet composition (FC)" problem demonstrating the FS/FC optimization method, which resulted in fleet utilization increase by 10-15\%. In [12], it was used an agent-based model of a flexible car-sharing system to find the fleet size along with maximizing the demand level that can be satisfactorily served. Paper [13] showed a possibility of multiple objective optimizations of the fleet size consisting of technical and economic criteria, as well as interests of different stakeholders through a two steps solution procedure and original software. In paper [14] an agent-based approach to fleet composition was taken. According to the technique, the fleet was presented as modular and conventional structures and several indicators were selected to quantify fleet performance including operation costs, total resupplied resources and fleet readiness. After applying an agent-based model including about 30 input parameters it was found that the resupplied resources for modular vehicle fleet operations showed a $40 \%$ decrease but other indicators of interest need to be further investigated. Paper [15] presented a successful multi-objective evolutionary algorithm (MOEA) in the maintenance scheduling of 50 vehicles and 13 components for each vehicle in various scenarios. As a result of the experiment, the authors concluded that the fuzzy logic was a more preferable solution to the conventional probabilistic approach. The MOEA algorithm based on the fuzzy modeling can solve the vehicle repair issues on a larger scale, which is a further research task. The use of the MATSim agent-based transport simulation of electric taxicab described in [16] led to the taxicab service optimization to dispatch the highest battery charge taxis first. The developed SCO-dispatch also reduced the battery charging time up to 23 minutes in contrast to the FIFO-dispatch to improve the taxi service level. An optimization model for fleet sizing and empty pallet allocation considering $\mathrm{CO}_{2}$ emissions was given in research [17]. The model embraces uncertain demand, storage capacity and rented vehicles. A particle swarm optimization algorithm with inertia weight (IPSO) showed that the amount of $\mathrm{CO}_{2}$ emissions from vehicles can affect the decision on fleet sizing and empty pallet allocation. It resulted in an average profit of $4570402 \mathrm{CNY}$ comparing to other (CPSO and branchand-bound method) techniques. Quite interesting studies can be noted on finding the fleet size in the rail transport as they use the universal techniques to be applied in other modes of transportation. Thus, studies [18-19] determined the railroad fleet by considering the fuzziness and randomness of the rail freight car demand. Authors [20] proposed a two-stage solution procedure to provide acceptable strategies for the size of railcar fleets and allocation of the freight cars. Authors of papers [21-22] demonstrated simulated annealing and genetic algorithms to generate the size and utilization of railcar fleet for periods of various railcar demands. Thus, from the analysis of sources, it can be concluded that there is no unified approach and criterion to the fleet size and composition to make this study relevant. Moreover, there are no mathematical dependencies (models) that can be taken to calculate the vehicle utilization rate without the of the transportation process simulation.

As seen from the above-stated, when determining the fleet number and its composition, the application of various optimization algorithms is impossible without software use. In turn, the software to implement the 
simulation modeling is of particular interest. Simulation modeling is an effective way to create realistic models since it fully embraces the external environment factors. According to [23], among the simulation modeling software, the AnyLogic product is the most modern and powerful tool for creating models for a wide range of tasks, which contains a built-in library for modeling objects and processes in transportation, as well as tools for generating the random variables and statistical processing of computer experiment results. In addition, the AnyLogic environment gives opportunities to provide experiments and automation of parameters (factors) variation according to the experiment plan. Researchers have been using the AnyLogic software in solving a significant series of problems related to freight, passenger and vehicular traffic organization in different modes of transport. Authors of [24] used the AnyLogic product in modeling and obtaining the performance parameters for transport servicing of the oil pipeline system. In article [25], there was an efficient simulation of a public transport stop functioning to determine its bus capacity under various conditions. Study [26] presented a two-stage optimization of intermodal terminals' main parameters via AnyLogic software combining the agent-based system dynamics simulation with the agent-based discrete-event simulation models to improve the decision-making process in selection of the terminals' strategic planning. Paper [27] described an AnyLogic-optimized vehicles' flow in a crowded urban area to obtain a travel time reduction for all road users. With the AnyLogic procedures, authors [28] developed and improved a "leagile" supply chain operation by shortening the supply chain length, accelerating the market demand response and personalizing the customers' needs. Article [29] reported successful passenger rolling stock maintenance by simulating various conditions of the rolling stock operation (maintenance facilities location, maintenance and repair costs, etc.) in the AnyLogic environment. In [30], the authors used the AnyLogic application to identify the warehouse performance bottlenecks by simulating the duration of operations under various scenarios. The bottlenecks revealed were picking and assembly processes while the processes in the inbound and kitting stations demonstrated a sufficient capacity. The use of electric vehicles in the urban delivery of goods is a relatively new phenomenon and this was the reason for the study [31] to compare the efficiency of electric and diesel cars by simulating their performance with the AnyLogic environment. Preliminary simulation experiment included the blocks of the electric vehicles, charging power and charging hubs to impact the retailer's operations. The results obtained for the electric fleet were the advanced urban delivery system survey and subsequent delivery system reorganization (determining the charging hubs number and location, order weight, electric vehicle capacity, increasing the number of observations, etc.). According to the authors, the above- stated efforts should increase the competitiveness of electric deliveries and reduce the carbon emissions significantly.

\section{Problem statement}

The vehicle utilization rate is an important indicator of the fleet operation, as it shows the part of working time for the cars taken directly to the freight transportation. Low-used vehicles may need maintenance, while the vehicles in operation may generate revenue and cover the repair costs.

There are various ways to assess the truck utilization rate; they include the vehicle miles travelled, analysis of days or hours of operation as a percentage of the total working time; the number of vehicles operated per day as a percentage of the available fleet.

From the above-stated, the truck utilization rate is proposed to be estimated as the "orders' total servicing time-to-the total working time" ratio

$U=\frac{T_{\Sigma}}{T w_{\Sigma}}$,

where:

$T_{\Sigma}$ is the orders' total servicing time, hours;

$T w_{\Sigma}$ is the total working time, hours.

Utilization is considered to be effective at the rate of 0.8 and, thus, requires some explanations. Firstly, the value of 0.8 reflects the fleet operational practice of the "BMZ BUD" LLC logistics company in Kharkiv (Ukraine) being the basis of the study, and, consequently, is used with the proper calculation purpose. Secondly, at a high utilization rate $(U \rightarrow 1)$ there is a situation when a significant percentage of orders will not be serviced due to a lack of free vehicles. Thirdly, for other results of interest, within the AnyLogic simulation procedure, this value can be easily changed in a range of $0-1$.

Therefore, the objective function is as follows

$U \rightarrow 0.8$.

The simulation modeling task of the vehicle operation is as follows. The warehouse (the $W$ point) receives the freight transportation orders of some intensity. After that, the car is loaded and the freight is transported to the customer (the $O$ point), then the car is unloaded and returned. Since the loading point capacity may not allow the queue-less process, this fact should be additionally considered in the model. The freight transportation is on the shuttle service. Based on the above, it is necessary to simulate the freight transportation process and determine the optimal values of the functioning parameters to ensure the target value of the truck utilization rate.

The duration of each component of the transportation process depends on many factors, which are due to 


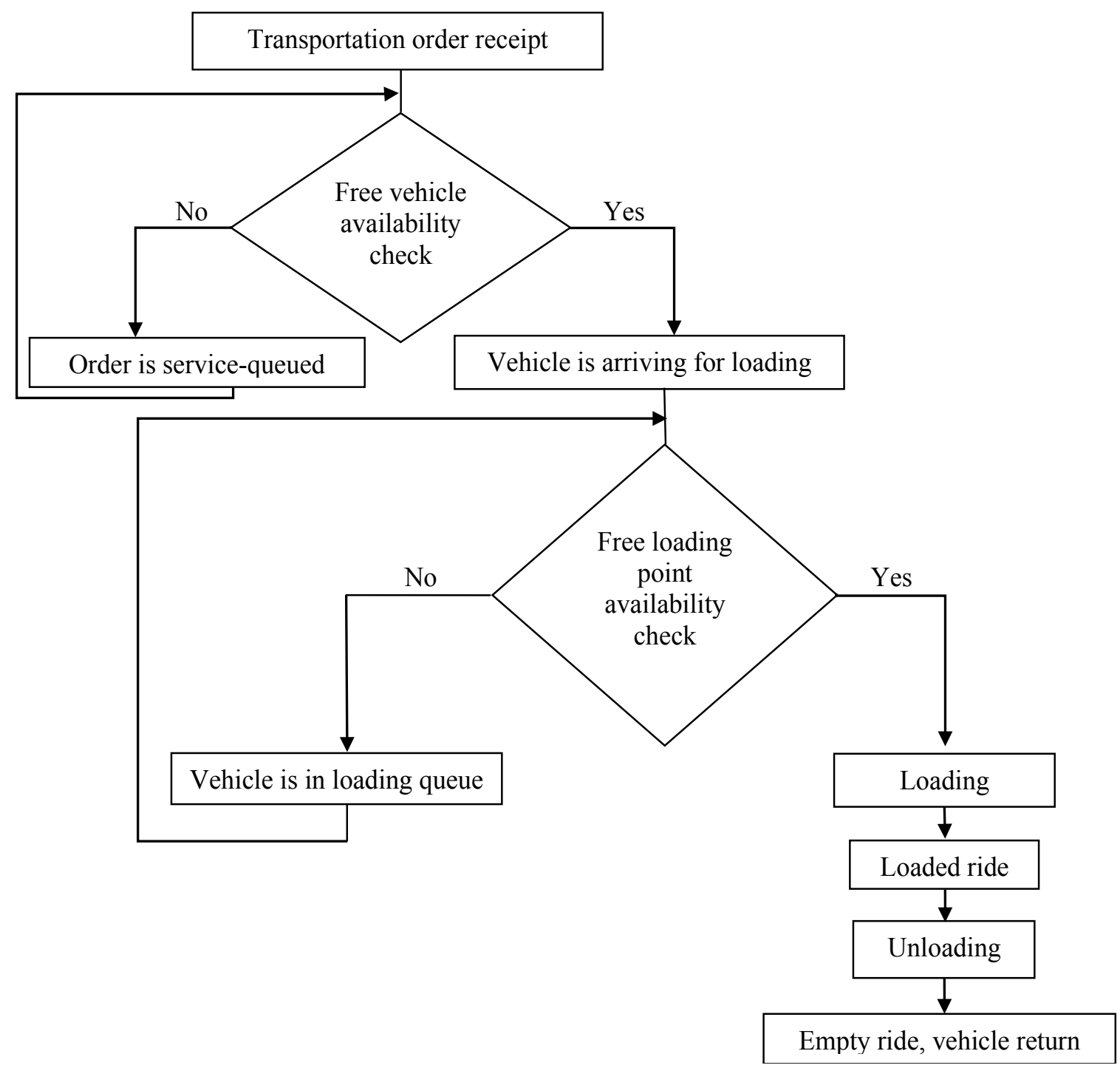

Figure 1 Transportation order completion process

its stochastic nature. In the model, the performance parameters - average road speed, vehicle loading and unloading time should be considered as the random variables. The input data are the number of trucks vehicles $(A)$, the intensity of orders $(N)$, the distance of transportation $(L)$. The output data is the truck utilization rate described above. The total transportation time per vehicle $\tilde{t}_{\Sigma}$ is calculated by the formula

$\tilde{t}_{\Sigma}=\tilde{t}_{q}+\tilde{t}_{l}+\tilde{t}_{W O}+\tilde{t}_{u l}+\tilde{t}_{O W}$,

where:

$\tilde{t}_{q}$ is the vehicle's waiting time in the loading queue (if available), hours;

$\tilde{t}_{l}$ is the vehicle's loading time, hours;

$\tilde{t}_{W O}$ is the travel time from $W$ to $O$, hours;

$\tilde{t}_{u l}$ is the vehicle's unloading time, hours;

$\tilde{t}_{\text {OW }}$ is the travel time from $O$ to $\mathrm{W}$, hours.

Thus, the truck utilization rate will also be a random variable.

Due to the significant influence of random factors, it is impractical to study the transportation order completion using the analytical methods only, but simulation modeling should be used. The order servicing process is presented in Figure 1.

\section{Simulation procedure description}

The AnyLogic 8 Personal Learning Edition 8.7.2 software was used to generate the simulation model. The simulation model sequence is presented in Figure 2.

Create a new model and set a model time minutes. To simulate the process, use the process modeling library, components from the "Agent" and "SpaceMarkup" palettes and the "Statistics" to collect the data.

Set the mutual location of the warehouse and customers using the "Space Markup". The agents are designed to simulate the warehouse, customers and vehicles. Simulate the customers' order generation process to receive a cargo via the "Statediagram". This is an intensity-described process.

When creating the order processing logic, it is 


\begin{tabular}{|c|c|c|c|}
\hline $\begin{array}{l}\text { Setting the } \\
\text { warehouse and } \\
\text { customers' } \\
\text { location }\end{array}$ & $\begin{array}{l}\text { Describing the } \\
\text { orders' } \\
\text { generation } \\
\text { process }\end{array}$ & $\begin{array}{l}\text { Describing the } \\
\text { orders' } \\
\text { processing } \\
\text { logic }\end{array}$ & $\begin{array}{l}\text { Setting the } \\
\text { numerical } \\
\text { parameter } \\
\text { values }\end{array}$ \\
\hline
\end{tabular}

Figure 2 Simulation model sequence

necessary to show that the vehicles are the warehouse resource to complete the order. To do this, open the previously created agent, with which the warehouse was set and from the "ProcessModelingLibrary" palette, transfer the "ResourcePool" block to the graphic editor field, then rename the block to "trucks". This block generates a set of available resources, i.e. trucks and calculates the truck utilization rate.

So, after receiving the order, the resource (truck) is taken, loaded and then sent to the customer and unloaded. After that, the truck returns to become a free resource.

In the AnyLogic environment, the creation of the technological process of transportation will be considered in detail. Briefly describe each diagram object that must be taken from the Process Modeling Library Blocks [32].

For the agent, the Seize block captures a specified number of resources from the "ResourcePool" block. To free the resource, use the Release block. Next, the agent is removed using the Sink block.

The "ResourceTaskStart" block indicates the beginning of the diagram that simulates the order completion process.

The Queue block is used to simulate the loading queue.

The Delay block delays agents for the predetermined time; its capacity is also set. With its

trucks

$97 \%$ ५५

$0 / 1$ use, simulation of the loading (unloading) process and the number of loading points are to be done. Rename the blocks to "loading" and "unloading".

With help of the "MoveTo" block set the vehicular traffic in the forward (MoveTo) and reverse (MoveBack) directions, the traffic speed is also set.

End the process diagram with the "Resource Task End" block.

The AnyLogic program provides a convenient tool for collecting statistics on the operation of the process diagram blocks. The statistics on the time to complete the order are collected using the blocks "TimeMeasureStart" and "TimeMeasureEnd" ("timeTotal") from the process modeling library. To measure the time spent by agents (vehicles) on a segment of the process diagram, place these blocks at the beginning and the end of the segment of interest, respectively. The first block keeps the time for the agent to pass through the block and the second block measures the time for the agent to spend on the segment of the process diagram after leaving the first block.

Numerical characteristics of different transportation processes have been obtained by researching the "BMZ BUD" LLC logistics company in Kharkiv (Ukraine).

The loading (unloading) time $T$ is simulated using the normal distribution law with the mathematical expectation of 0.25 hours and the standard deviation

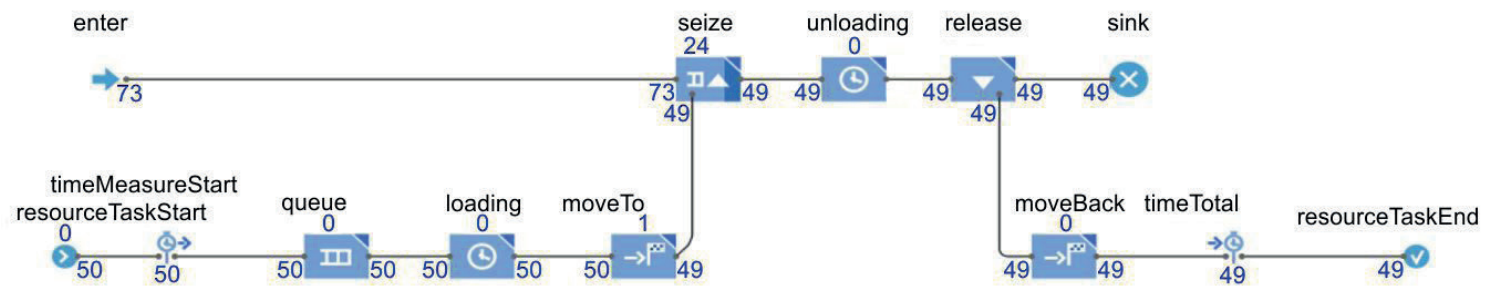

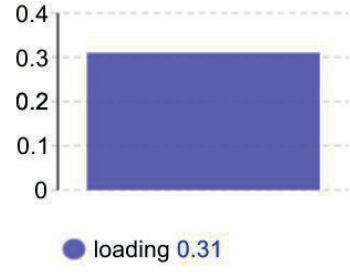
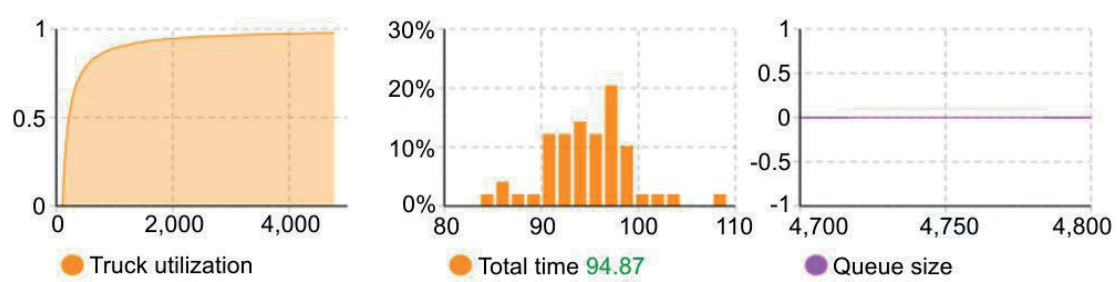

Figure 3 Test simulation results 
Table 1 Levels of variation

\begin{tabular}{ll}
\hline Factor & Variation of factors \\
\hline Transportation distance, $\mathrm{km}$ & $10 ; 20 ; 30$ \\
Number of vehicle, units & $1 ; 2 ; 3$ \\
Orders' intensity, unit/hour & $0.6 ; 0.7 ; 0.8 ; 0.9 ; 1$ \\
\hline
\end{tabular}

of 0.05 hours, i.e., $T \sim \mathrm{N}(0.25 ; 0.05)$ and the average road speed $-V_{t} \sim \mathrm{N}(50 ; 0.5)$.

Using the "Agent" palette component, set the numerical values of parameters to be automatically varied during experimental research, i.e. the number of vehicles (trucks) and the intensity of orders.

By default, the statistics are collected for all blocks of the Library. To display the truck utilization rate over time, add a graph to the diagram. The number of unprocessed orders, use of the loading device, length of the queue and distribution of the time are additionally calculated. Visualize the results of calculating the average use of the loading point (loading), length of the queue at the loading point (Queue size) and with a histogram, demonstrate the collected statistics of the total transportation time distribution (Total time).

For the test simulation, run the model under the following conditions: the number of vehicles is 1 unit/ hour, the intensity of orders received is 1 order/hour, transportation distance is $30 \mathrm{~km}$. Open the "Warehouse" agent and analyze the results. The results of the simulation model run are shown; the simulation time is $4800 \mathrm{~min}$, (see Figure 3).

In Figure 3 it can be observed that the truck is used by $97 \%, 24$ orders are unprocessed; the loading device use is 0.31 , the average order completion time is 94.87 $\min$

\section{Experimental research description}

Experimental research is aimed at obtaining the initial information to determine the dependencies in changing in the truck utilization on the distance of transportation, number of vehicles and intensity of orders, i.e.

$U=f(L, A, N)$

To conduct the research in AnyLogic, create a parameter variation experiment. To consider the randomness in the model, in the experiment "Properties" window it should be checked that the runs are unique and each iteration is of 100 replications.

For convenience, the data collected from the experimental results should be saved to the Microsoft Excel workbook. To do this, the "Excel file" component needs to be added to the experiment sheet and set to the utilization rate saving after each replication in the "Java
Actions" section. It is necessary to check the data saving when the model stops working. On the replication sheet, the Dataset should be created to collect the replication data.

The levels of variation of the input factors were determined $L \in$ [10;30], $A \in[1 ; 3], N \in[0.6 ; 1]$ to develop an experimental plan. Table 1 demonstrates the levels of variation for the experimental factors.

Thus, the $3 \times 3 \times 5=45$ series were obtained in the experiment.

To substantiate the required number of tests in the series of experiments, the pilot calculations were performed.

The pilot experiment was carried out for the lower and upper limits of factors for the distance of $10 \mathrm{~km}$, $20 \mathrm{~km}$ and $30 \mathrm{~km}$, thus obtaining 6 series. In each series of pilot experiments, 100 tests were done.

According to the pilot experiment results, the hypothesis on the normal distribution of the response function (truck utilization) was verified.

To verify the hypothesis, statistical processing of the results was performed using the Statgraphics Centurion 18 program. As a result of this processing, the hypothesis of a normal distribution of the response function was not rejected. The results obtained for the $6^{\text {th }}$ series of the pilot experiment are given in Figures 4 and 5).

As can be seen from Figures 4 and 5, the hypothesis of a normal distribution of the random value (truck utilization) is not rejected for all the series of the pilot experiment. Since the response function is described by the normal law, the sample size (number of tests) should be determined by the following dependence

$n=\frac{t^{2} \cdot \sigma^{2}}{\varepsilon^{2}}$,

where:

$t \quad$ is the quantile of the probability;

$\sigma$ is the standard deviation;

$\varepsilon \quad$ is the margin of sampling error.

The margin of sampling error is calculated as

$\varepsilon=(1-\beta) \cdot y$,

where:

$\beta \quad$ is the confidence level;

$y \quad$ is the response function arithmetic mean.

Here is a calculation example for the sixth series of the pilot experiment

$n=\frac{1.64^{2} \cdot 0.062^{2}}{((1-0.95) \cdot 0.56)^{2}}=13$. 

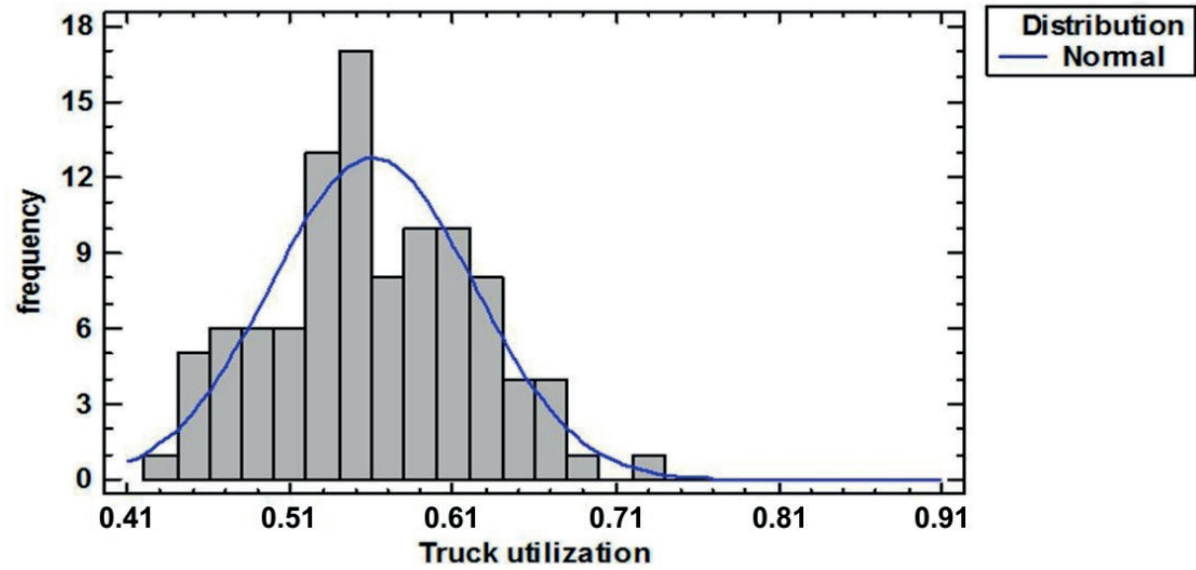

Figure 4 Truck utilization histogram

\section{Distribution Fitting (Uncensored Data) - Truck utilization}

Data variable: Truck utilization

100 values ranging from 0.437824 to 0.731449

Fitted Distributions

\begin{tabular}{|l|}
\hline Normal \\
\hline mean $=0.560549$ \\
\hline standard deviation $=0.0624442$ \\
\hline
\end{tabular}

standard deviation $=0.0624442$

\section{Goodness-of-Fit Tests for Truck utilization}

Kolmogorov-Smirnov Test

\begin{tabular}{|l|l|}
\hline & Normal \\
\hline DPLUS & 0.063937 \\
\hline DMINUS & 0.0479886 \\
\hline DN & 0.063937 \\
\hline P-Value & 0.808275 \\
\hline
\end{tabular}

Figure 5 Results of verifying the normal distribution hypothesis

Table 2 Calculation results of the required number of tests in series

\begin{tabular}{lccccccc}
\hline \multirow{2}{*}{ Parameter } & \multicolumn{7}{c}{ Variation of factors } \\
\cline { 2 - 7 } & 1 & 2 & 3 & 4 & 5 & 6 \\
\hline Mean value & 0.691 & 0.448 & 0.778 & 0.500 & 0.874 & 0.560 \\
Standard deviation & 0.094 & 0.058 & 0.097 & 0.057 & 0.093 & 0.062 \\
Required number of tests & 20 & 18 & 17 & 14 & 13 & 13 \\
\hline
\end{tabular}

The results for other series of the pilot experiment are summarized in Table 2.

Thus, in a series the 100 tests (replications) are sufficient. Using the model developed in the AnyLogic environment, in accordance with the developed plan, a simulation experiment, which includes 45 series of 100 experiments, should be conducted. The program window with the experiment is presented in Figure 6 .

\section{Results and discussion}

To establish a functional relationship between the input factors and the truck utilization rate, the regression analysis was applied. The Statgraphics Centurion 18 software to determine the coefficients of regression models when processing the results of experimental studies was used.

Hypotheses of functional dependences of the truck utilization rate on the distance of transportations, number of vehicles; the intensity of orders' receipt for the simulation time was formed as follows

$$
\left[\begin{array}{l}
H_{1}: U=a_{0}+a_{1} \cdot L+a_{2} \cdot A+a_{3} \cdot N, \\
H_{2}: U=a_{0}+a_{1} \cdot L^{2}+a_{2} \cdot A+a_{3} \cdot N^{2}, \\
H_{3}: U=a_{0}+a_{1} \cdot \frac{1}{L}+a_{2} \cdot A+a_{3} \cdot N,
\end{array}\right.
$$

where $a_{0}, a_{1}, a_{2}, a_{3}$ are the coefficients of regression 
Iteration

\begin{tabular}{lr} 
Replication & 26 \\
Parameters & \\
\hline numberTrucks & 2 \\
intens & 0.8
\end{tabular}

ㄴ. dataset

732 measurements ...[7, 0.648]

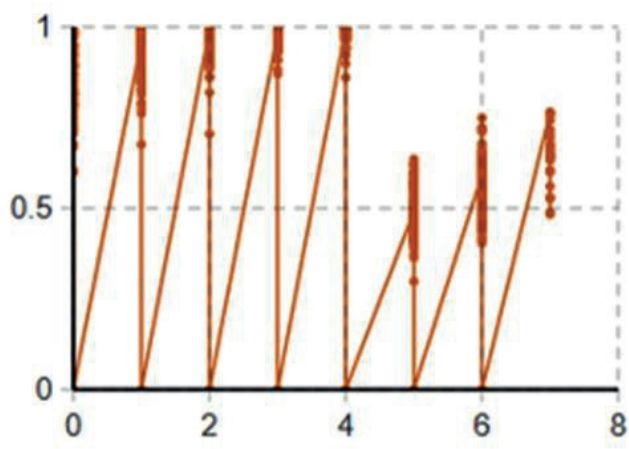

Trucks utilization

excelfile

File name C /Users/Anna/Des...

Figure 6 Experiment program window

Table 3 Results of testing hypotheses on the regression model type

\begin{tabular}{lccc}
\hline \multirow{2}{*}{ Regression parameter } & \multicolumn{3}{c}{ Hypotheses } \\
\cline { 2 - 4 } & $H_{1}$ & $H_{2}$ & $H_{3}$ \\
\hline$a_{0}$ & 0.57028 & 0.61064 & 0.77244 \\
$a_{1}$ & 0.00549 & 0.00013 & -1.51026 \\
$a_{2}$ & -0.25412 & -0.06040 & -0.25412 \\
$a_{3}$ & 0.55932 & 0.34534 & 0.55932 \\
$R$-squared & 0.95507 & 0.89227 & 0.95170 \\
Standard Error of Estimate & 0.05147 & 0.07970 & 0.05337 \\
Mean absolute error & 0.04320 & 0.06692 & 0.04358 \\
\hline
\end{tabular}

Table 4 Regression analysis results

\begin{tabular}{ccccc}
\hline Parameter & Estimate & Standard Error & $t$-Statistic & $p$-Value \\
\hline Constant & 0.570284 & 0.0514719 & 11.0795 & 0.0000 \\
$L$ & 0.00549345 & 0.0009397 & 5.84569 & 0.0000 \\
$A$ & -0.254124 & 0.0093974 & -27.0419 & 0.0000 \\
$N$ & 0.559325 & 0.0542561 & 10.309 & 0.0000 \\
\hline
\end{tabular}

Table 5 Analysis of variance

\begin{tabular}{cccccc}
\hline Source & Sum of Squares & Degree of freedom & Mean Square & $F$-Ratio & $p$-Value \\
\hline Model & 2.30947 & 3 & 0.769822 & 290.57 & 0.0000 \\
Residual & 0.10862 & 41 & 0.002649 & & \\
Total (Corr.) & 2.41809 & 44 & & & \\
\hline
\end{tabular}

models of the truck utilization rate for the simulation time.

It should be noted that additional transformations of input factors are required for the transition from nonlinear to linear functions.

The results of checking the hypotheses about the functional dependence of truck utilization rate on input factors are given in Table 3.

The functional relationship is most accurately described with the following relation

$$
U=0.570284+0.00549345 \cdot L-0.254124 \cdot A+
$$$$
+0.559325 \cdot N \text {. }
$$

The regression analysis results for the linear model are presented in Table 4.

The analysis of variance for the linear model is given in Table 5 .

As it can be seen in Table 5, the $p$-value is less than 0.05 , there is a statistically significant relationship between the variables at $95 \%$ confidence. The $R$-Squared 

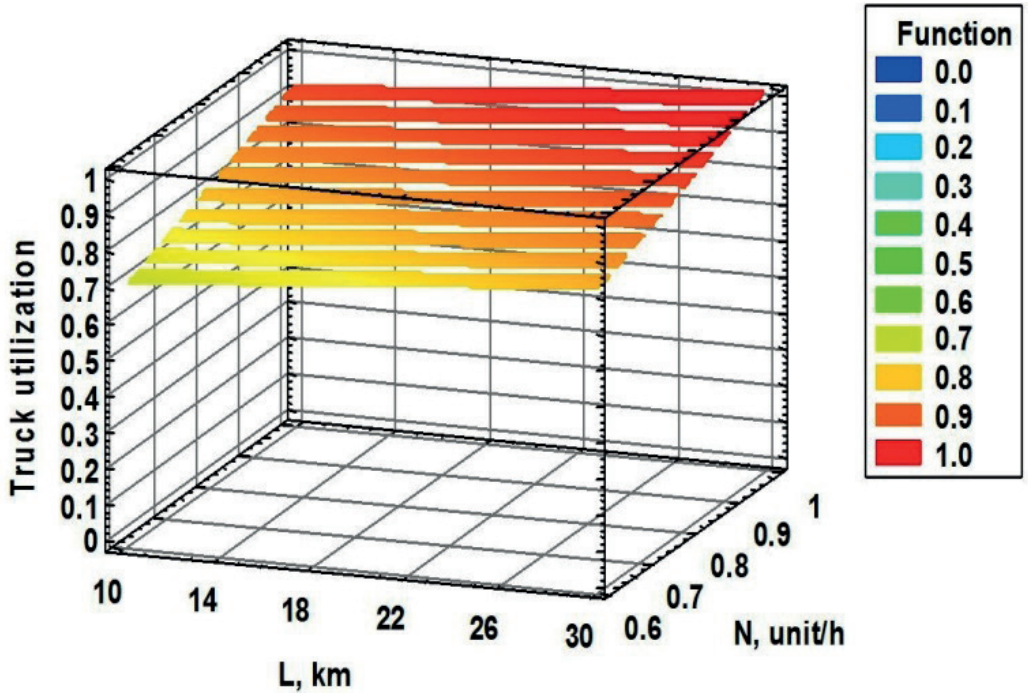

Figure 7 Truck utilization rate $(A=1)$

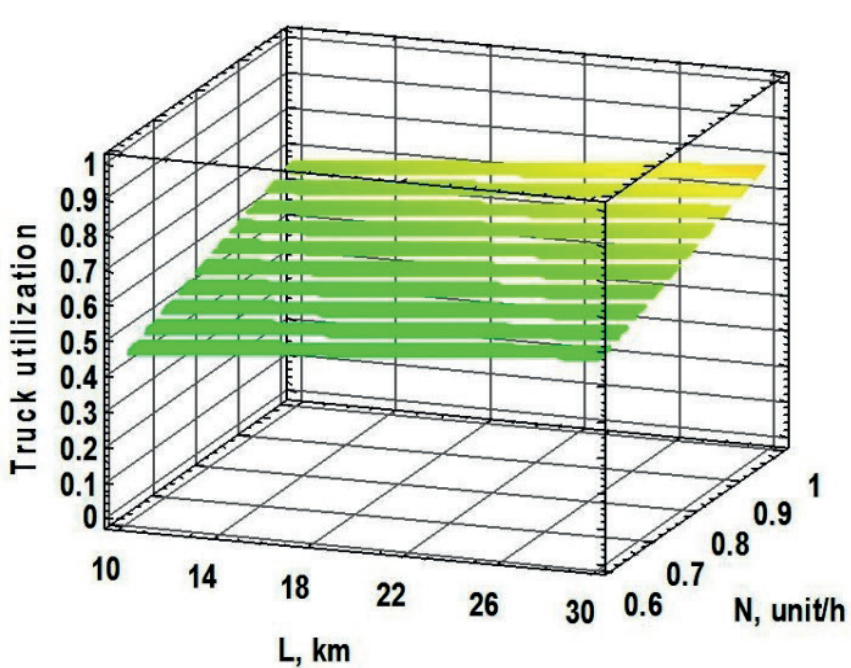

\begin{tabular}{|c|}
\hline Function \\
\hline 0.0 \\
0.1 \\
0.2 \\
0.3 \\
0.4 \\
0.5 \\
0.6 \\
0.7 \\
0.8 \\
0.9 \\
1.0 \\
\hline
\end{tabular}

Figure 8 Truck utilization rate $(A=2)$

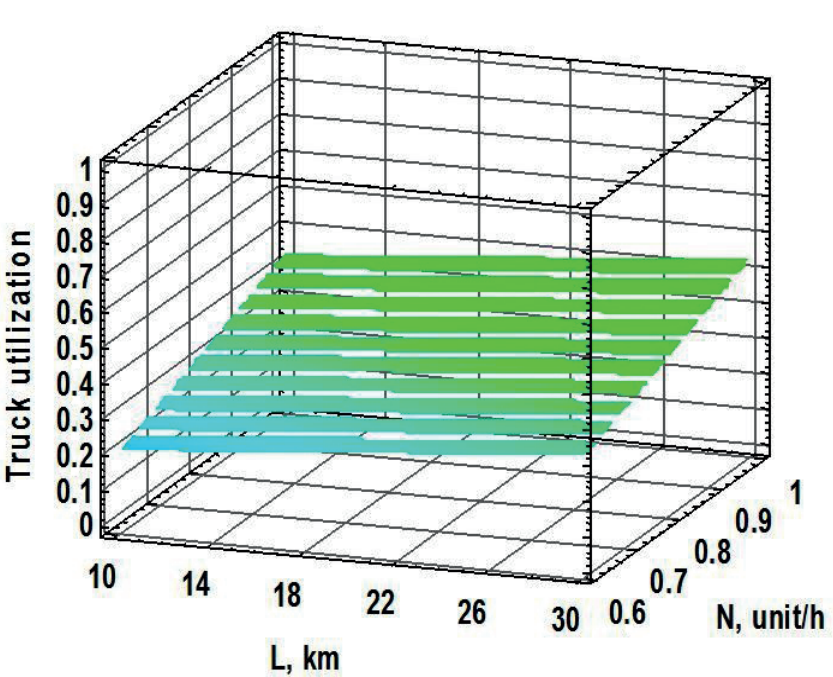

\begin{tabular}{|c|}
\hline Function \\
0.0 \\
0.1 \\
0.2 \\
0.3 \\
0.4 \\
0.5 \\
0.6 \\
0.7 \\
0.8 \\
0.9 \\
1.0 \\
\hline
\end{tabular}

Figure 9 Truck utilization rate $(A=3)$ 

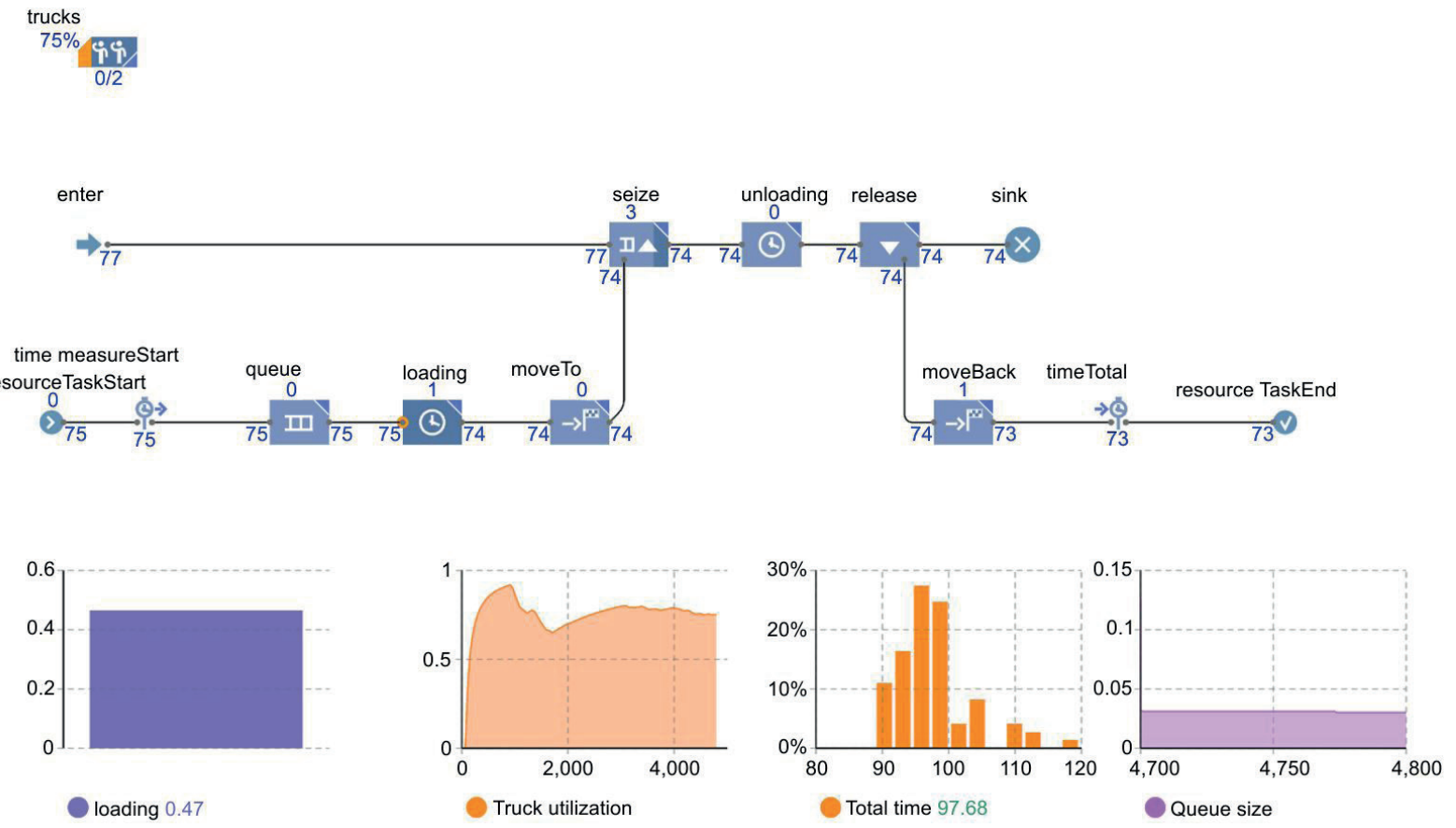

Figure 10 Simulation results at $A=2$

Table 6 Statistics of the transportation sub-processes

\begin{tabular}{cccccc}
\hline Agent & Parameter & Mean & Deviation & Minimum & Maximum \\
\hline Loading & Utilization & 0.465221 & 0.498789 & 0 & 1 \\
Queue & Queue Size & 0.030307 & 0.17143 & 0 & 1 \\
Time Total & Time distribution & 97.67971 & 5.923298 & 89.28624 & 119.3475 \\
\hline
\end{tabular}

Table 7 Time parameters of the transportation sub-processes

\begin{tabular}{cccccc}
\hline Block type & Name on the diagram & Mean seconds & Total seconds & Min seconds & Max seconds \\
\hline Delay & loading & 906.729 & 68921 & 492.322 & 1313.583 \\
Delay & unloading & 826.032 & 68013.3 & 521.591 & 1298.723 \\
MoveTo & moveTo & 2193.351 & 166720 & 1440.023 & 2279.595 \\
MoveTo & moveBack & 2245.153 & 170652.35 & 2210.839 & 2298.606 \\
Queue & queue & 456.8856 & 8680.826 & 17.889 & 1231.589 \\
\hline
\end{tabular}

(Table 3) indicates that the obtained model explains $95.36 \%$ of the variation in the truck utilization and, thus, provides a high quality of prediction. The dependences of changes in the truck utilization rate on the input parameters are given in Figures 7 to 9 .

From the analysis of the results presented, it can be found that at the availability of one vehicle there is an excess of the predetermined utilization rate for the most combinations of values of the input parameters. One vehicle should be used at a distance up to $20 \mathrm{~km}$ and intensity of orders up to 0.7 units/ hour (see Figure 8).

For the three vehicles, the utilization rate varies from 0.2 to 0.55 to indicate that more than half of the working time the cars are idle and negatively affect the income of the enterprise. Thus, for the range of the input data change, it is advisable to operate two cars, while the truck utilization rate will be directed to the target value. For the two vehicles and the maximum values of the orders' intensity and transportation distance, the order service process was simulated and the results are shown in Figure 10.

The process diagram demonstrates the main characteristics of the order service process and its subprocesses. Thus, the vehicle utilization rate is 0.75 , within the simulation runs 77 orders were received, 74 of which were served.

The detailed data was saved to a Microsoft Excel file and the statistics are presented in Table 6.

Table 7 provides the duration of the processes taken from the model run results.

Analyzing the data obtained, it is advisable to pay attention to the fact that during the loading there is an unproductive vehicles' idle time in the queue. Within the simulation runs its total value was 8680.83 seconds or 2.41 hours. 


\section{Conclusions}

The analysis results of the state-of-the-art literature and Internet sources showed many criteria for the fleet size estimation. The problem of finding the fleet size to meet the freight demand in different conditions stays an up-today issue. The vehicle fleet size was estimated in the paper according to the vehicle utilization rate, which was assigned as the "vehicle working time-to-total working time" ratio.

Advanced modeling and simulation methods were used for the contemporary solving of this problem. Considering the probabilistic nature of the transportation process, a simulation model to complete the orders by a truck fleet under a given operation has been developed in the AnyLogic environment. This approach provides more accurate results than the existing methods.

An experimental plan has been developed to reproduce the transportation order conditions and consisted of 45 series, each of which was of 100 experiments. The obtained results allowed to determine a regression model to decide on the fleet size with the stochastic flow of orders and considering the established restrictions.
The regression model for description of the vehicle utilization rate based on transportation distance, vehicle' number and orders' intensity was created. The obtained dependence has been estimated via the determination coefficient, which was 0.95 and indicated the high quality of the model proposed.

The proposed model can be used to calculate the vehicle utilization rate according to the known characteristics of the freight flow parameters without the applying of transportation process simulation. In accordance with the results, the freight fleet size is to be estimated according to the target value of the efficiency criterion. The obtained regression model outlines the conditions under which the vehicle fleet size can be efficiently used.

Research should be subsequently directed to consider a larger number of influencing factors, increasing their variation range and obtaining dependencies to describe the presented criterion change to acceptable accuracy. The simulation model presented does not take into account the operation of crews of vehicles where the vehicle's driving time should be limited and the work breaks, daily and weekly rest should be considered as the model constraints that are the tasks for further study.

\section{References}

[1] AULIN, V., HRYNKIV A., LYASHUK, O., VOVK, YU., LYSENKO S., HOLUB, D., ZAMOTA, T., PANKOV, A., SOKOL, M., RATYNSKYI, V., LAVRENTIEVA, O. Increasing the functioning efficiency of the working warehouse of the "UVK Ukraine" company transport and logistics center. Communications - Scientific Letters of the University of Zilina [online]. 2020, 22(2), p. 3-14. ISSN 1335-4205, eISSN 2585-7878. Available from: https://doi.org/10.26552/com.C.2020.2.3-14

[2] LUKASIK, Z., KUSMINSKA-FIJALKOWSKA, A., OLSZANSKA, S. Improvement of the logistic processes using the reverse logistics concept. Communications - Scientific Letters of the University of Zilina [online]. 2021, 23(3), p. 174-183. ISSN 1335-4205, eISSN 2585-7878. Available from: https://doi.org/10.26552/com.C.2021.3.A174-A183

[3] NAUMOV, V., ZHAMANBAYEV, A., AGABEKOVA, D., ZHANBIROV ZH., TARAN, I. Fuzzy-logic approach to estimate the passengers' preference when choosing a bus line within the public transport system. Communications - Scientific Letters of the University of Zilina [online]. 2021, 23(3), p. 150-157. ISSN 1335-4205, eISSN 2585-7878. Available from: https://doi.org/10.26552/com.C.2021.3.A150-A157

[4] BIELLI, M., BIELLI, A., ROSSI, R. Trends in models and algorithms for fleet management. Procedia Social and Behavioral Sciences [online]. 2011, 20, p. 4-18. ISSN 1877-0428. Available from: https://doi.org/10.1016/j. sbspro.2011.08.004

[5] HOFF, A., ANDERSSON, H., CHRISTIANSEN, M., HASLE G., LOKKETANGEN, A. Industrial aspects and literature survey: fleet composition and routing. Computers and Operations Research [online]. 2010, 37(12), p. 2041-2061. ISSN 0305-0548. Available from: https://doi.org/10.1016/j.cor.2010.03.015

[6] BEAUJON, G. J., TURNQUIST, M. A. A model for fleet sizing and vehicle allocation. Transportation Science [online]. 1991, 25(1), p. 19-45. ISSN 0041-1655, eISSN 1526-5447. Available from: https://doi.org/10.1287/ trsc.25.1.19

[7] DU, J. Y., BRUNNER, J. O., KOLISCH, R. Obtaining the optimal fleet mix: a case study about towing tractors at airports. Omega [online]. 2016, 64, p. 102-114. ISSN 0305-0483. Available from: https://doi.org/10.1016/j. omega.2015.11.005

[8] WU, P., HARTMAN, J. C., WILSON, G. R. An integrated model and solution approach for fleet sizing with heterogeneous assets. Transportation Science [online]. 2005, 39(1), p. 87-103. ISSN 0041-1655, eISSN 1526-5447. Available from: https://doi.org/10.1287/trsc.1030.0050

[9] LEJDA K., ZIELINSKA, E. Car fleet management problems in enterprise. TEKA. Commission of Motorization and Energetics in Agriculture. 2013, 13(1), p. 89-94. ISSN 1641-7739. 
[10] NAUMOV, V. Estimating the vehicles' number for servicing a flow of requests on goods delivery. Transportation Research Procedia [online]. 2017, 27, p. 412-419. ISSN 2352-1465. Available from: https://doi.org/10.1016/j. trpro.2017.12.063

[11] REDMER, A. Strategic vehicle fleet management - the composition problem. LogForum. 2015, 11(1), p. 119-126. ISSN 1895-2038, eISSN 1734-459X. Available from: http://www.logforum.net/vol 11/issue 1/no 11

[12] BARRIOS, J. A., GODIER, J. D. Fleet sizing for flexible car sharing systems: simulation-based approach. Transportation Research Record [online]. 2014, 2416(1), p. 1-9. ISSN 0361-1981, eISSN 2169-4052. Available from: https://doi.org/10.3141/2416-01

[13] ZAK, J., REDMER, A., SAWICKI, P. Multiple objective optimization of the fleet sizing problem for road freight transportation. Journal of Advanced Transportation [online]. 2011, 45(4), p. 379-427. ISSN 0197-6729, eISSN 2042-3195. Available from: https://doi.org/10.1002/atr.111

[14] XINGYU, L., EPUREANU, B. An agent-based approach to optimizing modular vehicle fleet operation. International Journal of Production Economics [online]. 2020, 228(C), 107733. ISSN 0925-5273. Available from: https://doi.org/10.1016/j.ijpe.2020.107733

[15] WANG, Y., LIMMER, S., VAN NGUYEN, D., OLHOFER, M., BACK T., EMMERICH, M. Optimizing the maintenance schedule for a vehicle fleet: a simulation-based case study. Engineering Optimization [online]. 2021, ahead-of-print. ISSN 0305-215X, eISSN 1029-0273. Available from: https://doi.org/10.1080/03052 15X.2021.1919888

[16] BISCHOFF, J., MACIEJEWSKI, M. Agent-based simulation of electric taxicab fleets. Transportation Research Procedia [online]. 2014, 4, p. 191-198. ISSN 2352-1465. Available from: https://doi.org/10.1016/j.trpro.2014.11.015

[17] JIANWEI, R., CHEN, C., GAO, J., FENG, C. An optimization model for fleet sizing and empty pallet allocation considering CO2 emissions. Plos One [online]. 2020, 15(2), e0229544. eISSN 1932-6203. Available from: https://doi.org/10.1371/journal.pone.0229544

[18] MILENKOVIC, M., BOJOVIC, N. A. fuzzy random model for rail freight car fleet sizing problem. Transportation Research Part C: Emerging Technologies [online]. 2013, 33.p 107-133. ISSN 0968-090X. Available from: https://doi.org/10.1016/j.trc.2013.05.003

[19] MILENKOVIC, M., BOJOVIC, N., SVADLENKA, L., MELICHAR, V. A stochastic model predictive control to heterogeneous rail freight car fleet sizing problem. Transportation Research Part E: Logistics and Transportation Review [online]. 2015, 82(C), p. 162-198. ISSN 1366-5545. Available from: https://doi.org/10.1016/j.tre.2015.07.009

[20] SAYARSHAD, H. R., TAVAKKOLI-MOGHADDAM, R. Solving a multi periodic stochastic model of the railcar fleet sizing by two-stage formulation. Applied Mathematical Modelling [online]. 2010, 34(5), p. 1164-1174. ISSN 0307-904X. Available from: https://doi.org/10.1016/j.apm.2009.08.004

[21] YAGHINI, M., KHANDAGHABADI, Z. A hybrid metaheuristic algorithm for dynamic rail car fleet sizing problem. Applied Mathematical Modelling [online]. 2013, 37(6), p. 4127-4138. ISSN 0307-904X. Available from: https://doi.org/10.1016/j.apm.2012.09.013

[22] SAYARSHAD, H. R., GHOSEIRI, K. A. simulated annealing approach for the multi-periodic rail-car fleet sizing problem. Computers and Operations Research [online]. 2009, 36(6), p. 1789-1799. ISSN 0305-0548. Available from: https://doi.org/10.1016/j.cor.2008.05.004

[23] VOLODARETS, M. V. Features of the AnyLogic application for solving problems of transportation simulation (in Ukrainian). In: Problems of mathematical education: challenges of the present. 2018, p. 280-283. ISBN 978-966641-733-9

[24] BAUER, V., BAZANOV, A., KOZIN, E., NEMKOV, V., MUKHORTOV, A. Optimization of technological transport sets using AnyLogic simulation environment. Journal of Mechanical Engineering Research and Developments [online]. 2019, 42(2), p. 41-43. ISSN 1024-1752. Available from: https://doi.org/10.26480/jmerd.02.2019.41.43

[25] LIPENKOV, A., KUZMIN, N. The determination of acceptable intensity level of movement of city buses in accordance with carrying capacity of a bus stop. Intellect, Innovatsii, Investicii. 2015, 3, 97102. ISSN 2077-7175.

[26] MURAVEV, D., HU, H., RAKHMANGULOV, A., MISHKUROV, P. Multi-agent optimization of the intermodal terminal main parameters by using AnyLogic simulation platform: case study on the Ningbo-Zhoushan Port. International Journal of Information Management [online]. 2021, 57, p. 102-133. ISSN 0268-4012. Available from: https://doi.org/10.1016/j.ijinfomgt.2020.102133

[27] COMAN, M., BADEA, D. The vehicles traffic flow optimization in an urban transportation system by using simulation modeling. Land Forces Academy Review [online]. 2017, 22, p. 190-197. eISSN 2247-840X. Available from: https://doi.org/10.1515/raft-2017-0026

[28] ZHANG, Y., WANG, Y., WU, L. Research on demand-driven leagile supply chain operation model: a simulation based on AnyLogic in system engineering. System Engineering Procedia [online]. 2012, 3, p. 249-258. ISSN 2211-3819. Available from: https://doi.org/10.1016/j.sepro.2011.11.027

[29] BANNIKOV, D., SIRINA, N. Model of passenger rolling stock maintenance. In: 10th International Scientific and Technical Conference Polytransport Systems: proceedings. 2018. p. 1-7. 
[30] FERRARI, A., ZENEZINI, G., CARLIN, A., RAFELE, C. An integrated simulation modelling approach for a warehouse 4.0 [online]. Available from: https://doi.org/10.21203/rs.3.rs-317679/v1

[31] UTOMO, D. S., GRIPTON, A., GREENING, P. Modelling home grocery delivery using electric vehicles: preliminary results of an agent-based simulation study. In: 2019 Winter Simulation Conference: proceedings. IEEE. 2019. ISBN 978-1-7281-3283-9, p. 1637-1648. Available from: https://www.informs-sim.org/wsc19papers/164.pdf

[32] Process modeling library blocks - The AnyLogic Company[online] [accessed 2021-03-23]. Available from: https://help.anylogic.com/index.jsp?topic=\%2Fcom.anylogic.help $\% 2 \mathrm{Fhtml} \% 2 \mathrm{Fprocessmodeling} \% 2 \mathrm{Fcustom}$ block.htm 